\title{
Doctors should be able to prescribe exercise like a drug
}

\author{
Few think that brief advice can change behaviour
}

\author{
David Nunan departmental lecturer \\ Nuffield Department of Primary Care Health Sciences, University of Oxford, UK
}

About a quarter of men and a third of women in the United Kingdom describe themselves as physically inactive. ${ }^{1}$ These make for worrying statistics, given that a sedentary lifestyle is responsible for about 5.3 million premature deaths a year globally. ${ }^{2}$

The UK medical royal colleges and others have called for healthcare professionals to help tackle the problem, ${ }^{3-5}$ urging primary care professionals to lead the fight and to "question patients about their physical activity and exercise habits at every meeting." 3

Such calls seem to be going unheard, however. Some $92 \%$ of 346 GPs and $99 \%$ of 206 nurses surveyed agreed or strongly agreed that promoting physical activity was important. ${ }^{6}$ But saying and doing are not the same thing: professionals instigate brief physical activity interventions opportunistically in only a quarter of appropriate instances, the National Institute for Health and Care Excellence has found. ${ }^{7}$ Also, as few as $46 \%$ of patients have reported receiving advice about physical activity and exercise from their GP. ${ }^{8}$

Clinicians' reasons for not giving such advice include time constraints, a lack of tools, and-in my opinion, a key factor-scepticism about whether such counselling actually works: only a third of healthcare professionals surveyed thought that their brief advice would be successful in changing patient behaviour. ${ }^{6}$

\section{Is exercise medicine?}

This scepticism includes doubt among practitioners and their patients about whether brief physical activity interventions count as medicine. The evidence for physical activity as medicine is predominantly underpinned by data from observational studies that are confounded in their estimated effects, ${ }^{9}$ which may not be replicated in randomised controlled trials. In addition, information on optimal "formulation" and "dosage" is scarce, ${ }^{10}$ as is information on where more evidence is needed and on which patients would benefit most from having physical activity prescribed.

These factors are likely to have a negative effect on the belief that exercise is medicine, if not on its application in practice.
A recent assessment of the quality of reporting and replication in trials of exercise based cardiac rehabilitation highlighted some of these issues and called for improvements in methodological reporting. ${ }^{11}$

A commentary offered viewpoints that echoed my own, such as, "[E]ffective translation of exercise as medicine goes beyond simply telling patients to 'exercise' or 'exercise several days a week" "and, "[P]roper implementation of exercise guidelines in clinical practice requires that exercise be prescribed for patients in a manner analogous to a drug prescription." 12

To aid this effort my colleagues and I are looking in detail at evidence in favour of physical activity for preventing and treating major chronic disease. ${ }^{13} \mathrm{We}$ have assessed 54 reviews of 20 medical conditions, including 1168 randomised controlled trials, 107706 participants, and more than 500 outcomes. The goals are to provide an overview of the quality of evidence for physical activity and exercise as medicine and to compile a much needed taxonomy of interventions that will help develop a formulary for prescribing physical activity.

Such scrutiny can yield better information about the benefits and harms of physical activity for prevention and treatment, but the act of scrutinising has value in itself. By applying the same standards of critical analysis to the evidence underpinning physical activity interventions as to those applied to drug treatments, healthcare practitioners will be more inclined to engage with the ethos and practice of prescribing physical activity and believe that "exercise is medicine."

I thank Kamal R Mahtani for comments on drafts.

Competing interests: I have read and understood BMJ policy on declarations of interests and declare the following: a significant proportion of my research has been supported by the National Institute for Health Research. I have no other competing interests to declare.

Provenance and peer review: Not commissioned; not externally peer reviewed.

Follow the author on Twitter, @dnunan79 British Heart Foundation. Physical activity statistics 2015. 28 Jan 2015. https://www.bhf.
org.uk/publications/statistics/physical-activity-statistics-2015. 
2 Kohl HW 3rd, , Craig CL, Lambert EV, et al. Lancet Physical Activity Series Working Group. The pandemic of physical inactivity: global action for public health. Lancet 2012;380:294-305. doi:10.1016/S0140-6736(12)60898-8 pmid:22818941.

3 Bailey V, Soni A, Alessi C, et al. The NHS's role in the public's health: a report from the NHS Future Forum. 2012. https://www.gov.uk/government/uploads/system/uploads/ attachment_data/file/216423/dh_132114.pdf.

4 Academy of Medical Royal Colleges. Exercise-the miracle cure. Feb 2015. www.aomrc org.uk/general-news/exercise-the-miracle-cure.html.

5 Royal College of Physicians. Exercise for life. 10 Sep 2015.https://www.rcplondon.ac.uk projects/outputs/exercise-life.

6 Hébert ET, Caughy MO, Shuval K. Primary care providers' perceptions of physical activity counselling in a clinical setting: a systematic review. Br J Sports Med 2012;46:625-31. doi:10.1136/bjsports-2011-090734 pmid:22711796.

7 National Institute for Health and Care Excellence. Physical activity: exercise referral schemes. NICE guidelines PH54. Sep 2014. https://www.nice.org.uk/guidance/ph54.

8 Department of Health. High quality care for all: NHS next stage review final report. CM 7432. Jun 2008. https://www.gov.uk/government/uploads/system/uploads/attachment data/file/228836/7432.pdf.
9 loannidis JP. Why most published research findings are false. PLoS Med 2005;2:e124. doi:10.1371/journal.pmed.0020124. pmid:16060722.

10 Bull F. CRA Physical Activity Work Group. Defining physical inactivity. Lancet 2003;361:258-9. doi:10.1016/S0140-6736(03)12290-8 pmid:12547568.

11 Abell B, Glasziou P, Hoffmann T. Reporting and replicating trials of exercise-based cardiac rehabilitation: do we know what the researchers actually did?Circ Cardiovasc Qual Outcomes 2015:8:187-94. doi:10.1161/CIRCOUTCOMES.114.001381 pmid:25737485.

12 Josephson RA, Mehanna E; American College of Cardiology. Exercise prescription: the devil is in the details. $11 \mathrm{Feb} 2016$. www.acc.org/latest-in-cardiology/articles/2016/02/11 devil is in the details. $11 \mathrm{Fe}$

13 Nunan D, Mahtani KR, Roberts N, Heneghan C. Physical activity for the prevention and treatment of major chronic disease: an overview of systematic reviews. Syst Rev2013;2:56. doi:10.1186/2046-4053-2-56 pmid:23837523.

Published by the BMJ Publishing Group Limited. For permission to use (where not already granted under a licence) please go to http://group.bmj.com/group/rights-licensing/ permissions 